\title{
The Basic Variety \\ (or: Couldn't natural languages be much simpler?)
}

\author{
Wolfgang Klein Max-Planck-Institut für Psycholinguistik \\ Nijmegen and Clive Perdue Université Paris VIII and \\ GdR 113 (CNRS)
}

In this article, we discuss the implications of the fact that adult second language learners (outside the classroom) universally develop a wellstructured, efficient and simple form of language - the Basic Variety (BV). Three questions are asked as to (1) the structural properties of the BV, (2) the status of these properties and (3) why some structural properties of 'fully fledged' languages are more complex. First, we characterize the BV in four respects: its lexical repertoire, the principles according to which utterances are structured, and temporality and spatiality expressed. The organizational principles proposed are small in number, and interact. We analyse this interaction, describing how the $\mathrm{BV}$ is put to use in various complex verbal tasks, in order to establish both what its communicative potentialities are, and also those discourse contexts where the constraints come into conflict and where the variety breaks down. This latter phenomenon provides a partial answer to the third question, concerning the relative complexity of 'fully fledged' languages - they have devices to deal with such cases. As for the second question, it is argued firstly that the empirically established continuity of the adult acquisition process precludes any assignment of the BV to a mode of linguistic expression (e.g.. 'protolanguage') distinct from that of 'fully fledged' languages and. moreover, that the organizational constraints of the BV belong to the core attributes of the human language capacity, whereas a number of complexifications not attested in the $\mathrm{BV}$ are less central properties of this capacity. Finally, it is shown that the notion of feature strength, as used in recent versions of Generative Grammar, allows a straightforward characterization of the $\mathrm{BV}$ as a special case of an I-language. in the sense of this theory. Under this perspective, the acquisition of an 1language beyond the BV can essentially be described as a change in feature strength.

Addresses for correspondence: Wolfgang Klein. Max-Planck-lnstitut für Psycholinguistik. Wundtlaan 1, Postbus 310, NL-6500 AH Nijmegen. The Netherlands, and Clive Perdue. Départment des Sciences du Langage. Université Paris VIII. 2 rue de la Liberté. F-93526 St Denis. Cedex 02. France. 


\section{Introduction'}

Natural languages, such as English, Chinese, Russian, are extremely complex systems. It takes the child about 10 years to master them 'perfectly', that is, as well as its social environment, and the second language learner hardly ever reaches this level of proficiency. Couldn't languages be much simpler? Linguists normally do not think about this question and, when urged to do so, they would probably take a Hegelian position - what is real is reasonable, and what is reasonable is real - and support a negative answer along one of two possible lines of argument: The complexity is due to inherent properties of the human language processor, hence necessary, or else it is needed for functional reasons, because otherwise language would not be as powerful an instrument as it is.

Both arguments are weak. The processing argument suffers from the obvious fact that we are able to process simple language. In fact, one might even say that the simpler the structure, the easier it is to produce and understand. There may be exceptions, but this is surely the rule. Therefore, the human language capacity provides us with the potential to process very complex structures but does not force us to do so. If the potential to become complex is exploited, then this must have different reasons, which have to do with what language is for: the simpler the language, the poorer its expressive power, and if complex thoughts are to be expressed, then the means to express them have to be complex, as well. This argument has a high degree of plausibility for the richness of the lexicon. If you want to talk about love and hate, about the good and the bad, then this is perhaps not impossible if you have not, but much easier if you have words such as love and hate, good and bad. But is it really necessary to have a dozen different noun paradigms, as in Latin? There are much simpler ways to mark case - if obligatory case marking is necesssary at all. German distinguishes three genders (der Löffel, die Gabel, das Messer), and most Germans take it for granted that such a distinction is a natural, if not necessary, thing to have. But speakers of English do not necessarily share this view. English, by contrast, systematically distinguishes two aspectual forms of the verb (he left, he was leaving) and this distinction has a clear functional value. It is a very

\footnotetext{
${ }^{1}$ Many thanks are due to Mary Carroll, Maya Hickmann, Ray Jackendoff and Anna Ramat for commenting on earlier versions of the article, and to all the members of the European Science Foundation's project on adult language acquisition for discussions over the years. Last but not least, we wish to thank our many informants for their co-operation and their patience.
} 
natural if not indispensable thing to have. But German gets along very well without such morphological complexities, and its speakers are somewhat reluctant to adopt them whenever they try to speak English. In French, the direct object follows the finite verb when it is lexical, and it precedes the verb when it is a pronoun \{Charlie voit la jeune fille - Charlie la voit). Couldn't one think of a simpler solution? French grammarians, before and after Hegel, would probably deny this; but other views are imaginable.

In this article, we shall not try to give a general answer to the question raised above - any such attempt would be totally speculative - but report some findings from second language acquisition which might shed some light on it, and thus on the question as to what are necessary and what are more accidental properties of the human language capacity. We shall describe a language which is simple and still extremely functional.

In the course of a large crosslinguistic, longitudinal project on adult second language acquisition outside the classroom, ${ }^{2}$ we noted that after some time, all 40 learners investigated developed a relatively stable system to express themselves which

- seemed to be determined by the interaction of a small number of organizational principles,

- was largely (though not totally) independent of the specifics of source and target language organization,

- was simple, versatile and highly efficient for most communicative purposes.

This system we call the Basic Variety (henceforth BV). For about one-third of the learners investigated, ${ }^{3}$ acquisition ended on this structural level; some minor variation aside, they only increased their lexical repertoire and learnt to make more fluent use of the BV.

We believe that the BV not only plays a particular role in the

\footnotetext{
${ }^{2}$ This project - 'Second Language Acquisition by Adult Immigrants' - took place from 1981 to 1988 in five European countries (France. Germany, Great Britain. The Netherlands and Sweden). It was co-ordinated from the Max-Planck-Institut für Psycholinguistik in Nijmegen, under the auspices of the European Science Foundation. For a comprehensive account, see Perdue (1993a; 1993b).

${ }^{3}$ It should be kept in mind that we are talking here about second language acquisition outside the classroom. No such system has ever been observed in second language acquisition in a classroom setting. The reason is simply that classroom acquisition not only reflects natural principles of the human language capacity - which lead to the BV - but also the effect of a particular teaching method, which, for example, may devote considerable time and effort to very specific features (say verb inflection). However, classroom learners of different language backgrounds have been observed to create and use outside the classroom - in the playground - a language of functional communication whose characteristics do seem to correspond to the BV (Bouton. 1969: 148).
} 
process of second language acquisition but also that it represents a particularly natural and transparent interplay between function and form in human language. In a way, fully fledged natural languages are but elaborations of this BV. They add some specific devices, such as inflectional morphology or focus constructions; they also add some decoration, pleasant to the ear, hard to learn, but faithfully handed down from one generation to the next. But essentially, they build on the same organizational principles. If this assumption is correct, then three questions must be answered:

1) What are the structural properties of the BV?

2) Why is it as it is?

3) Why are 'fully fledged' languages more complex than the BV?

In this article, we shall mainly deal with the first of these questions. In Section IV, we will try to characterize the BV in four respects: its lexical repertoire, the principles according to which utterances are structured, the expression of temporality and the expression of spatiality. In Section V, we will illustrate how the BV is put to use. These two sections sum up the results of a whole series of empirical studies. As is normally the case with empirical projects of this size, there is some variation, there are exceptions, and there are additional - supporting as well as disturbing - observations. In what follows, we shall try to carve out the main lines (for a full account, the reader is referred to the original studies - referred to below).

We have no answer to the second question, except the very general - and very strong - speculation that the BV simply and directly reflects the necessary, rather than the more accidental, properties of the human language capacity. This will be discussed in Section VI.2, in the broader context of what place the BV occupies within the human language capacity and how it relates to particular theories of this capacity, notably Generative Grammar.

As to the third question, we again have no full answer - but some empirically based ideas about what such an answer could look like. It has to do with the way in which speakers of the BV try to overcome conflicting organizational principles in particular communicative constellations. This will be discussed in Section V.2.

The idea of something like a 'Basic Variety' is not new. In one way or the other, it surfaces in earlier work on second language acquisition (Schumann, 1978; Klein and Dittmar, 1979; von Stutterheim, 1986). It is also found in the notion of a 'Basic Child Grammar' (Slobin, 1985), or in the idea that there might be a specific 'pragmatic mode', in contrast to a 'syntactic mode' (Givón, 1979), or even a 'protolanguage' (Bickerton, 1990). There are also obvious relations to pidgins and other forms of 'simplified' or 
'reduced' languages. These issues will be briefly discussed again in Section VI.3.

The BV is a type of language which, as far as we know, regularly develops during second language acquisition (outside the classroom). Our findings, and the way in which we interpret them, reflects a particular perspective on second language acquisition research which is somewhat at variance with the dominant view. A brief discussion of these two perspectives will be useful to explain why we feel that a concept such as the BV helps us to understand not only second language acquisition but the human language capacity in general. ${ }^{5}$

\section{Two perspectives on SLA research}

The study of language acquisition, and of second language acquisition in particular, is often led by the tacit but firm assumption that the learner's productions at any time of the acquisitional process are more or less successful attempts to reproduce the structural properties of target language utterances. The learner tries to do what the mature speaker does, but does it less well. Consequently, the learner's utterances are not analysed in their own right, according to their inherent structural characteristics, whatever these are, but in relation to the target language (TL). More precisely, they are analysed not in relation to the TL itself, but to some alleged structural characterization of TL which the researcher believes to be correct and appropriate. For example, the following four utterances are perceived not as constructions in their own right but as 'attempts to speak English', successful to the extent that they are understandable, but just 'bad English':

\footnotetext{
${ }^{4} \mathrm{~A}$ recent, comprehensive and balanced survey of the field of second language acquisition is Ellis (1994).

${ }^{5}$ We will not discuss, however, particular theories of SLA. for example 'parameter-setting' accounts of second language acquisition, as developed during the 1980s by a number of authors (see. for example, White, 1989: and for a more recent survey. Ellis. 1994: Chapter 7). This does not mean that we believe parameter-setting approaches are uninteresting: in fact, as shall be discussed in Section VI.2, an essential part of the BV can be characterized as a specifically parametrized form of language (or. more precisely. I-language). But first, present SLA accounts in the generative framework are based on versions of Generative Grammar which operate with principles and parameters that have largely become obsolete. Parameterized constraints on movement, such as Subjacency. for example, play no role in the feature theory of raising (cf. Section VI.2). Second, with very few exceptions (cf. n. 33). this work deals with SLA in the classroom, in which, for example, considerable attention is paid to the teaching of complex inflectional morphology. As we shall see below, the BV has no inflectional morphology, a point with considerable theoretical impact. Thus, whereas there are surely commonalities between SLA within and outside the classroom, there are also divergences in crucial respects, which render an immediate comparison highly problematic.
} 
1) Steal girl bread.

2) The girl stealed the bread.

3) Later, the girl has stolen the bread.

4) Which girl did John deny that has stolen the bread?

The 'deviations' from the TL standard may be massive or subtle: in (1), the 'underlying English syntax' is hardly recognizable, whereas in (2) it is 'almost correct' and (3) merely sounds a bit odd. 'Deviations' can vary with the linguistic background of the learner: the 'illegal extraction' in (4) is more likely if the speaker's mother tongue allows him or her to use such a construction. 'Deviations' are observed on all levels of linguistic competence pronounciation, morphology, syntax, choice of lexical items, all aspects of communicative behaviour. Accordingly, they are classified, counted and subjected to statistical analysis. Attempts are made to relate their occurrence (and sometimes nonoccurrence) and their distribution to various causal factors. The course and success of the acquisitional process are described in terms of decreasing divergences between TL utterances and the learner's attempts to reproduce them. The language of the learner at some given time is not so very much a language but rather an imperfect, deficient imitation of a language, and it is the latter which serves as the base of description. The 'learner variety' is not perceived and studied in terms of what it is but in terms of what it is not.

This target deviation perspective on language acquisition has found its most straightforward expression in classical 'error analysis', where, in its most elementary form, simply the hits and misses under varying conditions are counted, and a dichotomy created between 'error' and 'non-error'. But it is also taken by many other approaches, however much these differ in the methods by which the deviations are determined and in the causal considerations which are offered to explain them. This is not accidental. There are two important reasons which render the target deviation perspective very attractive. First, it provides the researcher with a straightforward design for empirical work. There is a yardstick against which the actual data can be measured. The target language, or rather the description of some of its aspects, is the base of reference, and what is measured are the differences between what the learner does and what this base of reference asks for. Second, it is the perspective of the teacher. Second language teaching is a normative process, and it is the teacher's responsibility to bring the learner as close to the norm as possible. From its very beginnings, second language acquisition research was inspired by 
the needs of foreign language teaching; it had, and still has, its focus in classroom learning: subjects are typically students of a foreign language. Thus, it is natural to take some norm as a stable base of reference and to investigate how and why the learner misses it. For example, the English learner of German must learn not to diphthongize long vowels, and to place the subject behind the verb if the object is fronted or if the sentence begins with an adverb. There are many reasons why it is important to do so. Exams in school may be failed, and in any contact outside the classroom there is the much more rigorous examination of the social environment which decides on the question: 'Is this person one of us?' Therefore, these and all other features of the TL must be precisely copied. Consequently, research on language teaching must try to understand to what extent and for which reasons learners have problems with perfect imitation. Hence, the target deviation perspective is perfectly natural in teaching research. But this does not mean that it is equally natural and rewarding when we want to know something about how the human language capacity functions and which principles determine the acquisitional process. ${ }^{6}$

In this article, we will advocate a different perspective for language acquisition research. ${ }^{7}$ It can be characterized by four key assumptions:

A) During the acquisitional process, the learner passes through a series of learner varieties. Both the internal organization of each variety at a given time as well as the transition from one variety to the next are essentially systematic in nature.

B) There is a limited set of organizational principles of different kinds which are present in all learner varieties. The actual structure of an utterance in a learner variety is determined by a particular interaction of these principles. The kind of interaction may vary, depending on various factors, such as the learner's source language. With successive input analysis, the interaction changes over time. For example, picking up some component of noun morphology from the input may cause the learner to modify the weight of other factors to mark argument status. From this perspective, learning a new feature is not adding a new piece to a puzzle which the learner has to put together. Rather, it entails a sometimes minimal, sometimes substantial reorganization of the whole variety, where the

${ }^{6}$ It is no surprise, therefore, that in first language acquisition, the target deviation perspective is rather the exception than the rule.

${ }^{7}$ This perspective has its historical roots in the late 1960s, when notions such as 'interlanguage' (Selinker. 1972) were first forged. Historically close notions are also Corder's (1967) 'simple code' and Clyne's (1968) 'Gastarbeiterdeutsch'. 
balance of the various factors successively approaches the balance characteristic of the target language.

C) Under this perspective, learner varieties are not imperfect imitations of a 'real language' - the target language - but systems in their own right, error-free by definition, and characterized by a particular lexical repertoire and by a particular interaction of organizational principles. Fully developed languages, such as English, German, French, are simply borderline cases of learner varieties. They represent a relatively stable state of language acquisition - that state where learners stop learning because there is no difference between their variety and the input - the variety of their social environment. ${ }^{8}$

D) If all learner varieties, including the final one, are manifestations of the human language capacity, then the study of this capacity should not start with the most complex of these manifestations, and go from there to the simpler ones. Rather, it is advisable first to study the various organizational principles of human language and their interplay in relatively simple cases, those where the various form-function relations are more elementary, and more transparent (if seen in their own right, and not as an imperfect imitation of the target).

The study of learner varieties and the way in which they evolve should therefore shed light on how linguistic systems function in general, including the most complex case of 'fully fledged' languages. Rather than taking the latter as a point of departure and working back in trying to understand how acquisition works, the study of language acquisition should help us to understand how the human language capacity functions - in its elementary manifestations no less than in the most complex cases it normally attains.

\section{Empirical background}

In this section, we will briefly sketch the project on which our empirical findings are based. The presentation concentrates on what seems indispensable for an understanding of the following sections. For details, the reader is referred to Perdue (1993a). ${ }^{9}$

\footnotetext{
${ }^{8}$ This does not mean, of course, that the process cannot come to a halt at a much earlier phase. First language acquisition normally stops when there is no salient difference between the learner's language and the language of the social environment: second language acquisition typically fossilizes much before - for example at the level of the 'BV'.

"See also Trévise and Porquier (1986) for methodological issues, and especially Feldweg (1993) for a detailed description of the transcribed and computerized data bank emanating from this project, whose results are based on the analysis of approximately 15,000 pages of transcription.
} 
The project was longitudinal, crosslinguistic, and it only dealt with second language acquisition outside the classroom. All our results are based on the productions of 40 adult learners of Dutch, English, French, German and Swedish (or a subset of these). All were recently arrived immigrants with legal status, and in daily contact with the language of their new social environment. ${ }^{10}$ Languages were organized as shown in (5), in order to control systematically for source language and target language effects.

5) The source language-target language combination

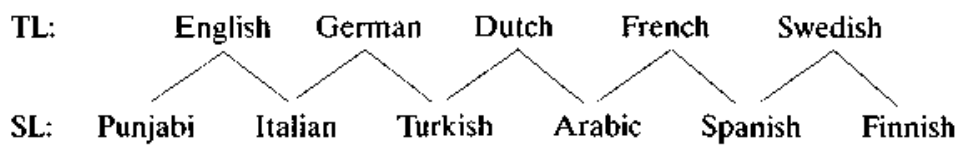

This comparison makes us all the more sanguine in reporting regularities which are independent of individual language pairings.

All learners were observed and recorded over a period of about 30 months. Various techniques of data collection were used; they were ordered into three data collection cycles, such that all learners performed each task at least three times. The present database consists of four 'complex verbal tasks' - film retellings, personal narratives, instructions ('stage directions') and picture descriptions - supplemented by selected passages of spontaneous conversation. In the 'stage directions' task, the learner instructs a naive interlocutor to move about, and to move objects from one place to another (as a director would instruct an actor), following a silently enacted scene which the learner has just observed. In the picture description task, the learner tries to make an interlocutor understand what is depicted on a picture which the interlocutor cannot see. In a personal narrative, the learner relates events in which he or she was involved at a specific moment in the past. In the film retelling task, the learner recounts the second half of an

\footnotetext{
${ }^{10}$ For the criteria for informant selection, see Chapter 3 of Perdue (1993a). The research design of the project allowed us to discern (through the inevitable variability encountered while studying real-life learners who acquire at their own pace) the shared structural characteristics of their progress from a noun-based utterance organization (Klein and Perdue, 1992; Dorriots. 1986; Perdue. 1987; Dietrich, 1989a; Perdue. 1996), right up to a finiteverb-based organization (Klein and Perdue, 1992; Perdue and Klein, 1992; Perdue, 1995; 1996). Not all learners attained this last stage. The 'plateau' referred to here as the BV represents a potential fossilization point. For the learners who indeed developed no further, this point was reached more than a year before the end of the observation period. Although, by definition, we know nothing of their development after the end of the observation period, it is as striking that this plateau is so similar, for so many learners, for such a long period of time (for a detailed discussion, see Perdue and Klein, 1992). as it is striking that the 'better' learners also pass through a stage where their learner variety is similarly structured.
} 
edited Charlie Chaplin film (Modern Times), the first half of which has been viewed by learner and interlocutor together. These tasks were run because piloting had shown that they provide ample linguistic material relevant to the research areas from which the present results are taken: temporal and spatial reference, and utterance structure. Thus the stage directions and description tasks consist in locating entities in relation one to another under various conditions, and the film retelling requires introduction of referents, and maintaining reference to them, under a wide range of semantic functions. Personal narratives have a clearly defined temporal structure. Accordingly, different types of data were used for different aspects of learners' production. The analysis of utterance structure is mainly based on film retellings, the expression of temporality was primarily studied in personal narratives, and the expression of spatiality used picture descriptions and the 'stage directions' task. In all cases, the data sets were cross-checked in relation to the other research areas, and extra data, in particular extracts from free conversations, were used wherever necessary (again, the reader is referred to Perdue, 1993a; 1993b, for details).

In the more guided tasks, the aim was both to obtain stretches of connected texts of different types, and also to have at least some control over what the learner was trying to communicate - the film clip, video recording and picture provide a degree of extra-linguistic correlational evidence of his communicative intentions. This is particularly important, if for one reason or the other, learner utterances deviate from the patterns commonly found. For example, Madan's: ${ }^{11}$

6) stealing bread girl (MPE)

'means' in context, the girl stole the bread, and not, e.g., that some unspecified agent stole the bread-girl; here, we have a particular constellation of case roles ('thematic roles') and focusing, which leads to a very specific structure; we shall return to this example in Section V.2. The systematic comparison with an external 'reality check' helped, at least to a certain extent, to resolve interpretation problems.

\footnotetext{
${ }^{11}$ Identification of examples is as follows: first letter is the informant's initial, second letter is his/her SL. third letter is the TL. Thus MPE means 'Madan, source language Punjabi, target language English'. The languages are to be found in example (5). All names of informants are pseudonyms. Some examples are glossed. These glosses, marked by \langle\rangle . are only meant to help understanding; they are never intended as a grammatical analysis of the example. + indicates a silent pause. $* *$ enclose borrowings from the source language, and [ ] enclose broad phonetic transcription.
} 
In-depth contextual interpretation is therefore necessary in order reliably to establish regular form-function correspondences. Once an interpretation has been established, the surest way of missing learner-language regularities is to imagine a 'corresponding' utterance in another language - the target language or the source language - then attribute its organization back to the learner's utterance (cf. the 'closeness fallacy'; Klein and Perdue, 1989). One cannot rely on TL sentence-internal functions such as 'subject', 'object', as this would amount to analysing the learner's language as if it were (imperfect) target language. Nor could we call on phenomena such as agreement and case, which are conspicuous by their absence from the BV, as we shall see. Thus the fact that 'the girl' is the grammatical subject of the 'corresponding' TL utterance to Madan's (6), does not a priori warrant 'girl' being given the status of 'subject' in Madan's own utterance.

\section{The structure of the Basic Variety}

\section{The lexical repertoire}

There is no inflection in the BV, hence no marking of case, number, gender, tense, aspect, agreement by morphology. Thus, lexical items typically occur in one invariant form. It corresponds to the stem, the infinitive or the nominative in the target language; but it can also be a form which would be an inflected form in the target language. Occasionally, a word shows up in more than one form, but this (rare) variation does not seem to have any functional value: the learners simply try different phonological variants. ${ }^{12}$

The lexicon in the BV varies in two respects - in size and origin. Normally, it increases steadily during the acquisition process, but this increase varies considerably from learner to learner (see Broeder, Extra and van Hout, 1993). The main source is normally the target language, of course. But there are also many borrowings from the source language; again, this varies from learner to learner, and generalizations are difficult.

Three types of regular interaction between source and target language systems are, however, worth mentioning. The first concerns the phonological form of the lexical item, which is often strongly influenced by the learner's mother tongue. This influence is very salient but not particularly interesting in the present context.

${ }^{12}$ Broeder. Extra and van Hout (1993) note random variation in the lemmatized BV lexicon, whatever the word class of the lemma, whereas in more advanced stages variation becomes confined to verb lemmas (in particular), as some learners develop a functional morphology. 
The second is at the borderline between lexical repertoire and structural principles - in word formation, more precisely in the relative order in hierarchical compounds of head and complement. Generally speaking, this order in the BV reflects that of the corresponding TL. In a well-documented study, Broeder, Extra, van Hout and Vojonmaa (1993) observe that the BV favours noun-noun compound constructions over derivational word formation (as do pidgins; cf. Mühlhäusler, 1986), and that the interplay of SL-TL particularities gives the following picture: noun-noun composition is determined by TL organization where this organization is unambiguous, but the more ambiguous the TL organization is, the stronger the impact of SL organization. Take the following attempts to refer to a baker in the film retelling. Learners of French coin compounds that are systematically head-initial (un monsieur la boulanger), as is TL-French. TL-Dutch allows both head-initial and head-final compounds; speakers of Moroccan (head-initial) tend to transfer their pattern (de baas van brood), whereas speakers of Turkish (head-final) coin head-final compounds (brood-baas).

The third example of a SL-TL interaction concerns the type of item used to express spatial relations. Again, this is determined by TL organization, as the French and German examples of Section IV.4.C below make clear. However, source language preferences emerge where the TL system offers a choice: Schenning and van Hout (1994) note, for example, that Moroccan learners of Dutch use prepositional phrases to express location and direction, whereas Turkish learners prefer TL adverbials to express these relations.

What does not vary is the composition of the lexicon. Essentially, it consists of a repertoire of noun-like and verb-like words, with some adjectives and adverbs (Dietrich 1989a; 1989b). ${ }^{13}$ The pronoun system consists of minimal means to refer to speaker, hearer and a third person (functioning deictically and anaphorically). Anaphoric pronominal reference to inanimates is not observed. There are a few quantifiers, a word for negation, a few prepositions with overgenerahzed lexical meanings, but no complementizers and, as has already been mentioned, no inflectional morphology, hence no markers of agreement, tense, aspect or case. In other words, the repertoire consists mainly of 'open-class', and a small list of 'closedclass' items with lexical meaning. There are some determiners (in particular demonstratives) but hardly ever a determiner system

"The longitudinal studies described in Section IV systematically investigated how each learner's linguistic repertoire was put to use at different points along the acquisition process. These repertoires may be consulted in Klein and Perdue (1992), Dietrich et al. (1995). Becker and Carroll (1997) and. for a quantitative study. Broeder. Extra and van Hout (1993). 
(Carroll and Dietrich, 1985), and there are no expletive elements, such as English existential there. Broeder, Extra and van Hout (1993) determine the relative share of each grammatical category in the learners' lexicon, and note that the share of articles, conjunctions and pronouns increases only after the BV stage. Parallel to this increase, there is a decrease in the share of nouns, adjectives and adverbs.

As usual in linguistic theory, lexical items should be seen as sets of feature complexes - phonological, semantical, grammatical, perhaps others. Grammatical features include categorial properties (being a noun, a verb, etc.), but also case-role features (or 'thetafeatures'), such as 'requires an agentive argument and a theme argument', etc. In what follows, we shall not systematically discuss these and other features. But it should be clear that whenever we speak of a lexical item such as bread or steal, this is just an abbreviation of a set of feature complexes.

\section{Utterance organization}

Given the lexical repertoire, how do speakers of the BV put its items together, when they produce an utterance? We found that their utterance structure is determined by the interaction of three types of constraints (or, as we often say, organizational principles):

1) There are absolute constraints on the form and relative order of constituents: phrasal constraints. ${ }^{14}$

2) There are constraints which have to do with the case role properties of arguments: semantic constraints.

3) There are, finally, constraints which have to do with the organization of information in connected text (introduction and maintenance of reference, topic-focus-structure): pragmatic constraints.

The phrasal constraints observed in the BV admit three basic phrasal patterns with some subvariants (the subscripts of $\mathrm{NP}_{1}$ and $\mathrm{NP}_{2}$ correspond to differences in their possible internal structures, set out below):

\footnotetext{
${ }^{14}$ It is these constraints which correspond to what is commonly called 'syntax' in the narrower sense of this word - that is. constraints that narrow down the ways in which larger units can be made of more elementary units and which are stated without reference to semantic or pragmatic factors. But since one also might have a broader understanding of what 'syntax' is. we prefer the label 'phrasal constraints' (see also Section VI.2).
} 


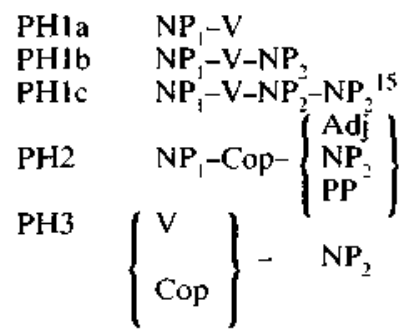

All patterns may be preceded or followed by an adverbial, normally an adverbial of time or space. They may also be preceded by the conjunction and (or its counterpart in other languages). Note that there is only one V-final construction used by all learners: PH1a. ${ }^{16}$ The BV shows a 'non-finite utterance organization': utterances contain verbs, and are structured according to the valency of this verb (where arguments may be left implicit under conditions specified below). But there is no trace of finite verbs, in whatever function.

The phrasal constraints impose strong restrictions on possible sentence structures. Note, however, that a pattern such as NP-V-NP does not mean that the first NP is the 'subject' and the second NP is the 'object'; in fact, it is not easy to define these notions within the BV - except by their alleged parallelism to target (or source) language utterances. Hence, the question arises which argument takes which position. We found that the assignment primarily follows a simple (semantic) principle which is based on the control asymmetry between referents of noun phrases: one can rank each argument of a verb by the greater or lesser degree of control that its referent exerts, or intends to exert, over the referents of the other argument(s). Strength of control is a continuum (Comrie, 1981; but also see note 18), depends on the semantics of the verb and is reflected in its case role properties (or theta-features). ${ }^{17}$ Strength

\footnotetext{
${ }^{15}$ The three subpatterns of PH1 only differ by the number of NP-arguments: they can easily be collapsed into $\mathrm{NP}_{1}-\mathrm{V}-\left(\mathrm{NP}_{2}-\left(\mathrm{NP}_{2}\right)\right)$. But it is perhaps more helpful to the reader if we keep them apart.

${ }^{16}$ Some learners, though, also use the pattern NP-NP-V. It is only attested in the English of Punjabi, but not Italian learners, and in the German and Dutch of Turkish, but not Moroccan or Italian learners. It is the case that Punjabi and Turkish, but not Moroccan and Italian are predominantly verb-final, although alternative word orders are not uncommon. While this pattern thus clearly reflects SL influence, such influence is rare overall. From a longitudinal perspective, use of this particular pattern is restricted, and these learners also acquire PH1b.

"It is perhaps arguable whether features such as 'is an agent' (in the case of an NP) or 'requires an agent as argument' (in the case of a verb) should be called 'semantical' or not. We have done so. because in one way or the other they have something to do with the meaning of the verb - with the type of action, process or event that it describes. But nothing hinges on this terminology.
} 
ranges from clear agent-patient relations at one extreme (with verbs such as hit, break) to weak asymmetries (with verbs such as kiss, meet) and finally to complete absence at the other extreme (as in copular constructions). Where control obtains, the following constraint can be observed:

SEM1 The NP-referent with highest control comes first

Hence the NP with the more agentive referent appears in initial position. The $\mathrm{NP}_{1}$-referent is therefore most often human (agentive referents tend to be animate; Silverstein, 1976), but human referents may also appear in $\mathrm{NP}_{2}$-position: semantic role properties, rather than intrinsic features of NPs, are crucial in assigning position.

Some verbs, notably verbs of saying and of giving, take three arguments (four arguments are never observed in the BV). These verbs are regularly of the 'telic' type, that is, their lexical meaning involves two distinct states as a part of their lexical meaning (cf. Klein, 1994: Chapter 5). What is crucial is the fact that the control relation between the various arguments is not the same in both states. This is best illustrated by an example such as Santo's:

7) Charlie give present for young children (SIE)

There is a first state, the 'source state', in which Charlie 'controls' the present, and is active in bringing about a distinct state, the 'target state'. In the target state, 'young children', not Charlie, control (i.e., 'have') the present. The control status of the NP which refers to the present is low in both states. Therefore, the principle 'Controller first' requires that this argument not come first (its exact position in the utterance will be specified below in Section IV.4.b). It does not say, however, which controller - the one of the source state or the one of the target state - comes first. Therefore, 'Controller first' has to be supplemented by an additional constraint, which defines the relative weight of source and target state in determining word order. It is:

\section{SEM2 Controller of source state outweighs controller of target state}

These considerations apply analogously to verbs of saying if we assume that what changes in both states is 'the control of information'. There is one referent who is in control of the information in both states, and another referent who does not control the information in the source state but only in the target 
state. Thus, the 'sayer' comes first, the hearer comes second, and the 'said' comes last. (Speech is directly quoted in the BV.)

The two control constraints impose additional restrictions on the way utterances can be put together. But they are not always operative, either because there is no asymmetry between the NPreferents, or because the verb has only one argument. ${ }^{18}$ In the following examples from Ramon, there is no control asymmetry. Nevertheless, the constituent order variation is not random:

8) a. il [setruv] avec la fille (RSF)

$<$ he (= Chaplin) finds himself with the girl>

b. il [setruv] avec Chaplin (RSF)

<'he" (= the girl) finds herself with Chaplin>

c. il arrive (RSF)

<he arrive>

d. arrive *otra* personne (RSF)

<arrive other person>

Some examples from the acquisition of Dutch illustrate the same point:

9) a. hier is die cafe (MMD)

<here is that cafe>

b. dan auto is hier (MMD)

<then car is here>

c. die meneer valt van water (FMD)

<that mister fall from water, i.e., Charlie fell into the water>

d. met valt drie (FMD)

<with fall three, i.e., there were three of them fell>

In copular constructions, and for verbs which take only one argument, NP position depends on the way in which information is distributed over an utterance in context; that is, by pragmatic factors.

The pragmatic constraints which we found in the BV are of two types. They may have to do with information status, i.e., which information in the utterance is new and which is maintained from the preceding utterance(s), on the one hand, or with the topic-focus structure, on the other. These two factors must be carefully kept apart, although in practice they often go hand in hand. The topicfocus-structure reflects the fact that a part of the utterance defines a set of alternatives to be decided (the 'topic') and then selects one

\footnotetext{
${ }^{18}$ This argument is certainly in a semantic relation to the verb - it has a 'case role' or 'thetarole' - and can be 'in control" in the sense that Comrie (1981) uses this term, but (i) there is no control asymmetry, and (ii) the semantic relation remains constant whether the argument is preverbal or postverbal (pattern PH1: 'Charlie arrive' or pattern $\mathrm{PH} 3$ : 'arrive Charlie').
} 
of those which is claimed to hold (the 'focus'). This idea, which goes back to authors such as Weil, von der Gabelentz and Paul in the last century, can be made more precise in various ways. This has been done in recent work on focus in formal semantics (see, for example, von Stechow, 1991; Rooth, 1992). The details are complicated and not relevant for our purpose; therefore, we shall only explain the basic idea by a simple example. The utterance The girl stole the bread can be used as an answer to (at least) three different questions:

10) a. Who stole the bread?

b. What did the girl steal?

c. What did the girl do?

In (10a), the alternatives are the persons that could have stolen the bread - this is the topic, repeated in the answer by stole the bread - and the focus is the person specified by the NP the girl. In (10b), the topic is the set of things that the girl could have stolen, and the focus constituent the bread specifies one of them - the focus. In (10c), the set of alternatives are all the events involving the girl that could have happened on that occasion, and the verb phrase specifies the one selected from this set - the focus. ${ }^{19}$

The particular status of an expression as focus expression or topic expression can be marked by specific devices such as intonation, clefting, or sometimes (as in Japanese) special particles. In the BV, it is mainly by word order. The relevant constraint is very simple:

\section{PR1 Focus expression last}

The argument of one argument verbs has a semantic role, but there is no semantic role asymmetry and, hence, the controller constraints cannot apply Thus, only PR1 and phrasal constraints interact: if the

${ }^{19}$ Both pragmatic factors - introduction and maintenance of information and topic-focusstructure - can be brought together if we assume that not just individual utterances but the entire text to which they belong constitutes an answer to a quaestio - an explicit or implicit question (Klein and von Stutterheim. 1987). Thus, a question such as 'What does your flat look like?" can be answered by a single utterance (It looks like a pigsty) but also by an organized sequence of utterances. Not all of these are direct answers to the initial 'quaestio'. i.e.. give (partial) descriptions; there may be all sorts of supportive information. commentaries, etc. Accordingly, the text may be partitioned into a main structure (the familiar 'foreground" in narratives) and various side structures. Different quaestiones lead to different text types, e.g., personal narratives ('What happened to you yesterday?'), argumentations ('Why should one marry? Are there several gods?'), directions ('How do 1 get to the station from here?'), etc. The quaestio determines the structure of the text which answers it in different ways: it defines the partitioning into main structure and side structures, the way in which the information flows from one utterance to the next ('referential movement'), the topic-focus structure of all main structure utterances, etc. 
referent of the NP is topical, then pattern PHI is used; if it is in focus then pattern PH3 is used. This is the difference between (8c) and (8d) above. The same constraint stipulates the NP's position in symmetrical (and therefore copular) constructions, as in examples (8a) and (8b): in the former, the girl is in focus; in the latter, it is Chaplin. Note that this interaction determines word order without reference to ill-defined notions such as 'subject' or 'object', but it explains the 'topic ingredience' often found in the subject (cf. Keenan, 1976; Reis, 1982).

The pragmatic constraint PR1 also governs other aspects of utterance structure, in particular the place of adverbials. We only give the main lines here. Time adverbials may occur in utteranceinitial position, most clearly in narratives. An utterance in the main structure (the 'foreground') of a narrative answers a 'quaestio' such as What happened at time $t_{\mathrm{x}}$ ? Thus, the topic of a foreground utterance contains a time span $t_{x}$, and the focus is the event that happened at that time. Therefore, a time adverbial specifying the time span of the 'quaestio' occurs naturally with pattern $\mathrm{PH} 3$, giving Adv-V-NP. A background clause, by contrast, may answer an implicit question such as When did this happen? In this case, it is the specification of the time span which is in focus and, hence, an adverbial which specifies this time span comes in final position. Similar considerations apply for spatial adverbials, for example in descriptive texts (see Section V.l). Time and space adverbs are, then, not 'preposed' (from where?), but occur where their topic or focus status dictates. ${ }^{20}$ Indeed, BV utterances can contain two adverbs of the same type, one in topic position, one in focus position; Starren (1996) examines pairs such as altijd ik wakker om acht uur (<always I wake-up at eight o'clock〉, MTD), to which we shall return in Section IV.3 below.

The other pragmatic factor which influences the structure of the utterance is the 'given-new distinction': Is whatever some expression refers to maintained from a preceding utterance, or is it new? In fact, this distinction interacts with the topic-focus status and results in different types of NPs. These, in turn, are restricted to certain positions, as indicated by the numbers in the phrasal rules PH1 to PH3 above. Here, we find some (limited!) variation within the BV. In particular, we find some numerals and - though rarely - a definiteness marker, mostly a demonstrative; we have marked

\footnotetext{
${ }^{20}$ The topic-focus structure also plays an important role in some other respects, not discussed here in detail. Thus, negation and (other) scope particles occur at the topic-focus boundary. This position can be marked: Santo and Ravinder use [iz(a)] (Huebner. 1989). Ergün (TD) uses is + V (Klein and Perdue. 1992), Abdelmalek (MF) uses 'li' (Véronique. 1983). See also Huebner (1983).
} 
this in the following diagram by optional Det. ${ }^{21}$ As a rule, however, nouns are bare. Thus, the main lines are as follows:

$\begin{array}{ll}\mathrm{NP}_{1} & \mathrm{NP}_{2} \\ \text { proper name } & \text { proper name } \\ \text { (Det) noun } & \text { (Det) noun } \\ \text { pronoun } & \\ 0 & \end{array}$

Choices among these forms depend on whether a referent is introduced or maintained, and whether the referring expression is in topic or focus. The most general opposition lies between use of a lexical noun (or proper name), on the one hand, and 0 (or pronoun), on the other. The latter is exclusively used to maintain reference in the context of movement of a controller from topic to topic in successive utterances. For some learners, the conditions under which zero anaphor occurs are even more highly constrained: the antecedent has to be the only potential controller, i.e., if the preceding utterance contains two human referents, then reference to the controller is maintained by a full noun in topic. Zero anaphor is not possible in place of de mädch in the second utterance of Angelina's:

11) de mädch gucke de mann mit brot <the girl look the man with bread> und de mädch wolle essen (AIG) <and the girl want to eat>

Maintenance of semantic role and position (controller first) is thus not in itself sufficient to license zero where there are two potential controllers in the previous utterance (and is a further indication that 'subject of is not a BV function). With names and lexical nouns, the topic/focus status of the referent is indicated solely by position. It follows from the observed distribution that reference maintenance in focus cannot be achieved by pronominal means. So, there are clear constraints on how things can be expressed in the BV, and where, consequently, its speakers might meet problems. These problems, we believe, are a major source of structural complexification, a point to which we shall return in Section V.2.

\footnotetext{
${ }^{21}$ We also occasionally find an adjective before or after $\mathrm{N}$ and a PP following the initial head in a compound.
} 


\section{The expression of temporality ${ }^{22}$}

Time and space are probably the two most fundamental categories of human cognition and, accordingly, all human languages have developed rich means to express them. In most languages - for example, in all source and target languages of the present project - the finite verb has to mark tense, aspect, or both; hence, with each normal sentence, the speaker has to refer to time, whether he or she wants to or not - it is an obligatory category. This is normally not the case for spatial information, but its structural and communicative importance is beyond doubt. In this section, we will discuss how temporality is expressed with the means of the $\mathrm{BV}$; the next section will be devoted to space.

The main data source for the investigation of temporality were personal narratives, embedded in conversations. They were completed by other conversational passages where informants speak about their future plans. Just as in other domains, the acquisitional process turns out to be continuous and gradual, without sharp boundaries between the various learner varieties. Here, we only consider the BV. Some minor variation aside, it can be characterized by four features:

1) As was set out in Section IV.1, utterances typically consist of uninflected verbs, their arguments and, optionally, adverbials. This means that the BV lacks the usual grammatical means to express tense and aspect.

2) Lexical verbs show up in a 'base form', and there is often no copula. Most learners of English use the bare stem as their base form, but V-ing also occurs. Learners of other languages may use the infinitive (German, French) or even a generalized inflected form (as often in Swedish). Turkish learners of Dutch, for example, use the infinitive, Moroccan learners of Dutch use the bare stem.

3) There is a fairly rich repertoire of temporal adverbials. Minimally, this repertoire includes: (a) the calendar-type adverbials (Sunday, in the evening); (b) anaphoric adverbials expressing the relation AFTER (then, after), and also typically an adverbial which expresses the relation BEFORE; (c) some deictic adverbials such as yesterday, now, (d) a few frequency adverbials, notably always, often, two time, etc; (e) a few durational adverbials, normally as bare nouns, such as two hour, etc. Temporal adverbials involving two reference points such as

\footnotetext{
"The empirical findings reported in this section are based on joint work by Rainer Dietrich, Colette Noyau and Wolfgang Klein. A detailed analysis is found in Dietrich et al. (1995). See also Noyau ( 1990).
} 
again, still, already do not belong to the standard repertoire of the BV.

4) There are some boundary markers, which allow the learner to express the beginning and the end of some situation, as in constructions like work finish, 'after work is/was/will be over'.

Compared to the rich expressive tools for temporality in fully fledged languages, this seems to impose strong restrictions on what can be said. This impression, however, is premature. At this stage, learners are often extremely good storytellers, and telling a story requires the expression of all sorts of temporal information. Their guitar, so to speak, has only one string, but they play it with masterly skill. How is this possible?

What the BV allows, is the specification of temporal relations such as BEFORE, AFTER, SIMULTANEOUS, etc. In particular, it allows the specification of some time span $t$ (in relation to some other time span s, for example the time of utterance). It can also express duration and frequency of time spans. Suppose that some time span $t$, about which the speaker wants to say something, is introduced. Such a time span will be called 'topic time' (abbreviated TT). The topic time is simply the time about which the speaker wants to make an assertion - in contrast to the 'time of the situation' (abbreviated TSit) - that is, the time at which the event, process or state to be situated in time obtains. All the speaker has to do is to introduce and, if there is need, to shift, TT, and to relate TSit to it. ${ }^{23}$ More systematically, the functioning of the $\mathrm{BV}$ is described by the following three principles:

I At the beginning of the discourse, a time span $\mathrm{TT}_{1}$ is fixed. This can be done in one of three ways:

(a) by explicit introduction on the informant's part; this is usually done by a temporal adverbial in initial position, in topic;

(b) by explicit introduction on the interviewer's part (e.g.. what happened last Sunday?);

(c) by implicitly taking the 'default topic time' - the time of utterance; in this case, nothing is explicitly marked.

\footnotetext{
${ }^{23}$ We assume that the notional category of TENSE expresses the relation of TT to the time at which the utterance is made - the deictically given time of utterance. The notional category of ASPECT expresses the relation between TT and TSit (Klein. 1994). Note that this definition of aspect is not at variance with other, more metaphorical characterizations of aspect, as often found in published work: it only makes them more precise. Take, for example, the case that the time about which an assertion is made is fully included in the time of the situation (TT IN TSit). This gives the feeling that the situation is 'viewed from the interior', 'as ongoing, in its development' - it is 'imperfective'. If. by contrast. TSit is fully included in TT. then this gives the impression that the event, state, process, is 'presented as a whole, as completed, as seen from the exterior' - it represents 'perfective aspect'.
} 
$\mathrm{TT}_{1}$ is not only the assertion time of the first utterance. It also serves as a point of departure for all subsequent assertion times in the text.

II If TT is given, then $\mathrm{TT}_{\mathrm{i}+1}$ is either maintained or changed. If it is maintained, nothing is marked. If it is changed, there are two possibilities:

(a) the shifted assertion time is explicitly marked by an adverbial in initial position:

(b) the new assertion time follows from a principle of text organization. For narratives, this is the classical principle of chronological order 'Unless marked otherwise, the order of mention corresponds to the order of events'. ${ }^{24}$ In other words, $\mathrm{TT}_{\mathrm{i}+1}$ is some interval more or less right-adjacent to TT..

This principle does not obtain in all text types. It is only characteristic of narratives and other texts with a similar overall temporal organization - texts which answer a question like What next? Even in these texts, it only applies to foreground sequences. In other text types, such as descriptions or arguments, the principle of chronological order does not apply, nor does it hold for side structures in narratives, i.e., those sequences which give background information, evaluations, comments, etc. For those cases, change of TT must be marked by adverbials.

Principles I and II provide the temporal scaffold of a sequence of utterances - the time spans about which something is said. The 'time of situation' TSit is then given by a third principle:

III The relation of TSit to TT in the BV is always 'more or less simultaneous'. TT can be contained in TSit, or TSit can be contained in TT, or TT and TSit contained in each other.

Thus, the various aspectual distinctions often observed in fully fledged languages are collapsed in the BV. However, within this simultaneity, cleverly managed combinations of adverbs and Aktionsarten of verbs allow learners to distinguish habituality from iterativity:

12) a. altijd ik les om half twee (MTD) <always I lesson at half past-one>

b. vandaag ik altijd weg met auto (FMD) $<$ today I always away with car>

For habituality (12a), one TSit is linked to a series of TTs, whereas for iterativity (12b), a complex TSit is linked to one TT (Starren, 1996).

${ }^{24}$ See. for example. Clark. 1971: Labov. 1972; von Stutterheim. 1986. 
This system is very simple (compared to what we find in all source and target languages) but extremely versatile. It allows an easy expression of when what happens, or is the case - provided that (a) there are enough adverbials, and (b) it is cleverly managed. Therefore, one way the learner has of improving his or her expressive power is simply to enrich vocabulary, especially by adding temporal adverbials, and to perfect technique on this instrument. And about one-third of the 40 learners whose acquisition was investigated do exactly this: they do not go beyond the BV, but they steadily improve it in these two respects - more words, better practice, no unnecessary complications. Speakers of the BV can say what they want to say about temporal relations not what the structure of the language forces them to say.

\section{The expression of spatiality ${ }^{25}$}

a Theme, relatum and spatial relation: In fully fledged languages, the expression of space is no less complex and varied than the expression of time: there are adverbs, prepositions, case marking, verbs of posture and of movement, and other devices available to express such complex messages as The second suspect from the left pulled this little gun out from under the chair behind the table over there. In the $\mathrm{BV}$, the expression of spatial relations is reduced to its basic ingredients. These are:

- the entity which is located, the theme;

- the entity in relation to which it is located, the relatum;

- the spatial relation which obtains between theme and relation, for example those expressed by at, behind, under, to the left of, etc.

It is useful to distinguish between static locations and changes of location, where the latter involve two positions \{source position and target position) of the theme. Thus, The book is on the table is static: the book is the theme, the table is the relatum, and the spatial relation is described by on. The utterance The book was put on the table is a dynamic event, with the source state characterized by 'book not on table' and the target state characterized by 'book on table'. The theme can be an object, a person, but also some event (a case normally not observed in the BV). The relatum is some entity which is assumed to be known to speaker and listener, or

\footnotetext{
${ }^{25}$ We have drawn on the work of Mary Carroll and Angelika Becker in writing this section, and refer the reader to Carroll (1990). Carroll and Becker (1993) and Becker and Carroll (1997) for a full analysis of the expression of spatial relations by these learners. Further details on TL Dutch come from Schenning and van Hout (1994). and on TL French, from Giacobbe (1993).
} 
else must be explicitly mentioned; it can be deictically given, or lexically specified.

Many spatial relations between theme and relatum are possible, and languages differ as to which ones they encode (Haviland and Levinson, 1994; Klein, 1991). Which ones of these can be expressed is essentially a matter of the lexicon, hence subject to considerable variation. Since the lexicon of the BV largely stems from the language to be learnt, there is some variation in this respect. Nevertheless, learners share some clear preferences for which relations they express. What is (quite) constant across learners is the structure of (dynamic and static) spatial expressions - a fact which brings us back to the constraints on utterance structure of Section IV.1. We first discuss the structure and then the lexicon.

$b$ The structure of spatial expressions: In the expression of space, the BV operates exactly with the constraints discussed in Section IV.1. But the concrete results depend on whether one or two spatial constellations are to be expressed. In the static case, the phrasal pattern is PH1b, for verbs of posture, and otherwise PH2 (copula constructions). The situation is more complex for change of location. Here, speakers distinguish whether only the theme's change of place is described ('locomotion', PH1b), or whether a potential controller, who causes the change of location, is mentioned as well ('causative motion', PH1c). We illustrate the latter case by returning below to the discussion (Section IV.1) of verbs of giving. Major constituents of these patterns may be left implicit where the context allows recoverability of information, and these contexts will be examined in more detail in the following section.

We saw in Section IV.1 that for verbs of saying learners observe a strict division between reported speech and its frame: reported speech comes after mention of speaker and addressee. For verbs of giving, a different constraint is at work. These verbs are a subclass of the verbs of causative motion (there is a parallel between 'John gave the book to Mary', and 'John put the book on the table'), where a theme undergoes a movement from a source (the controller) to a target position. The constraint:

\section{SEM3 Theme before relatum in target position}

operates for all verbs of causative motion, in all text types, as we shall see below in Section $\mathrm{V}$, and reflects the absence of indirect object cliticization in French, or dative movement, in English, from 
the BV. Note that SEM3 regularly maps the relatum on to $\mathrm{NP}_{2}$ of patterns $\mathrm{PH} 1$, which implies that, for causative motion, the relatum is always in focus, even if mutually known.

c Spatial relations: What are the spatial relations that are normally encoded in these patterns of the BV? In general, perceptual space is characterized by dimensional and by topological relations. ${ }^{26}$ The former are given by the speaker's co-ordinate axes: vertical (up-down), lateral (left-right), sagittal (front-back). These normally vary with the speaker's perspective on the relatum, including the case where the speaker himself/herself is taken to be the relatum (as in the case in spatial deixis). The topological structure has to do with the inclusion of (the place of) the theme in the place of the relatum (or the neigbourhood of the relatum). It is based on spatial relations which are invariant: use of such relations is therefore not dependent on entities or places with specific features (asymmetrical sides), nor on a particular perspective. The most neutral topological relation may be termed AT-PLACE: the theme is somehow 'with' the relatum, for example there where the relatum is, or is at its 'canonical position' in relation to the relatum. (In English, for example, people canonically sit 'at tables', but 'in cars'.) Some languages of the sample specifically encode this relation, others do not, but for the everyday world such canonical relations are often visually perceptible and understood, thus obviating the communicative need for explicit encoding. The AT-PLACE of a theme-relatum relation may be more finely divided into a set of topological subspaces, among which the following are often encoded:

- the INNER space,

- the EXTERIOR space,

- the BOUNDARY space, comprising a boundary (typically coinciding with the outer surface of the relatum),

- the NEIGHBOURING space.

A region of space may be delimited in terms of two relata, defining a relation of INTERPOSITION, but (just as with temporal adverbs involving two reference points) such an expression involving two relata is absent from the BV. Dynamic spatial configurations additionally require the notion of the PATH of an entity in motion, whose trajectory determines three subspaces: the SOURCE (from), INTERMEDIATE (along) and GOAL (to): a specification of these

\footnotetext{
${ }^{26}$ This is a very simplified picture of spatial relations, but it suffices for an analysis of what is normally expressed in the BV. For a more detailed discussion, see Klein (1991). Giacobbe (1993).
} 
(sub)relata functions to indicate the DIRECTION of a moving theme.

In the BV, all speakers - with minor exceptions - denote the same set of spatial relations in the same contexts: the BV contains more highly differentiated means to express dynamic as opposed to static constellations, and to express topological as opposed to dimensional relations. We will take each opposition in turn:

1. Static descriptions in the BV are mainly confined to the opposition between AT-PLACE and NEIGHBOURING, with a subset of learners expressing a finer distinction than AT-PLACE, namely, IN. The neutral relation AT-PLACE may be expressed by the fixed order theme-relatum - if nothing is made explicit, the neutral spatial relation is intended - or by an overgeneralized preposition: en, avec (Fr), met (Du), and the exact (canonical) relation is inferred. NEIGHBOURING is rendered by a transparent form, namely 'side' (côté, Seite, kant) in all basic varieties, independently of the grammatical status of this usage in the TLs. That subset of learners who express IN restrict its use to relata which can be conceptualized as containers, and use the AT relation in other contexts (see example 18). There is no expression of the relation EXTERIOR, presumably as it is communicatively more economical to relate the theme to another relatum.

All learners use a lexical item which corresponds to English there, i.e., a lexical item which merges the topological relation AT with a deictically or anaphorically given relatum, to be interpreted as 'not here'. It is interesting that the positive counterpart - the word which would correspond to English here is only found in the lexical repertoire of some speakers of the BV. We have no clear explanation for this asymmetry. It may be that here is communicatively less important to express, as it is the 'default' relation to the speaker's origo. The lexical repertoire for dimensional relations is much more restricted. A subset of learners expresses vertical \{top/bottom; en haut/en bas; oben/unten, boven/beneden) and lateral (left/right; gauche/droite; links/rechts), and less so sagittal relations (front/back; face; voor/achter) in static contexts.

2. Changes of location are expressed explicitly by a variety of terms simultaneously encoding a topological or dimensional component. We give some examples from French and German: 
13) French

away from source: [sorti], [part]

to goal: [ariv], [vj ]

from inner to outer/outer to inner space: [ãtr], [sorti]

upward/downvvard/leftward/rightward: [mõt], [desãd], à gauche, à droite

straight ahead: en face

along unbounded path: [pas]

14) German

away from source: raus, weg

to goal: bis, nach, $z u$

back: zurück

from inner to outer/outer to inner space: raus, zurück

upwards: auf

These examples clearly show the influence of the TL system on learners' analysis: the French items are mainly derived from TL verbs, whereas the German items are derived from TL prepositions or particles. (The only motion verb systematically used by learners of Dutch or German is 'come': komen/kommen.) The relative richness of lexical items for dynamic cases, in relation to that of static ones, is not an artefact of the data analysed, since learners were faced with a task requiring static relations to be expressed the description task. However, many chose to acquit themselves by expressing direction, and turned a description into a guided tour.

\section{The Basic Variety in use}

\section{Its functioning .. .}

How is this BV put to use in complex verbal tasks? We have already seen how a personal narrative is organized, and give here two further illustrations of how learners proceed: in the retelling, and in the stage directions task.

In the film retelling, learners narrate a complex overall event whose foreground comprises singular events, each of which answers the quaestio: What happens (with $p$ ) at $\mathrm{T}_{i+1}$ ?, where $\mathrm{T}_{\mathrm{i}}$ expresses one of a series of time intervals, and $\mathrm{p}$ a protagonist (in this particular elicitation task, Charlie Chaplin, and other characters). Learners construct this foreground obeying the principle of chronological order (recount the events in the order they occur), and by using pattern PH1a-c in contexts of referential "flow': inter-utterance cohesion is observed in the use of anaphoric forms (pronouns or 0) in $\mathrm{NP}_{1}$. Pattern PH3 is used to signal that there is a break. The NP is never a pronoun in this pattern: its referent is in focus, and 'answers' a question of the form 'What happens at $t_{i+1}$ ?, where no 
protagonist is presupposed (compare Labov's 'Then what happened?', 1972: 370). This is why a time adverbial associates naturally with this pattern, in topic: it functions either to indicate a major temporal break ('after ten days'), or to indicate, redundantly, that the upcoming utterance expresses a break in the event chain and/or the protagonists involved. An utterance such as Andrea's

15) after + comeback the brigade fire (AIE)

$<=$ then the fire brigade arrived $>$

is characteristic of this use of the adverbial - here introducing an 'arrival on the scene' - in a context where the temporal structure of the retelling does not really require one.

In the stage directions task, the spatial configuration 'themerelation-relatum' maps on to the three-argument (causative motion) variant of pattern $\mathrm{PH} 1$, as we saw above, with optional $\mathrm{V}$ and $\mathrm{NP}_{1}$. The speaker must draw the hearer's attention to the entity to be moved (thus making it identifiable for the hearer), convey the type of action required in the transition, and the new location of the entity at goal. Reference is therefore first made to the entity to be moved before the entity designating its position at goal. The performer (controller) need not be referred to, as in Zahra's

16) [ame] le chapeau avec le tabouret (ZMF) $\langle$ (put?) the hat with the stool'>

If expressed, the verb of causative motion normally precedes the theme, but such motion can also be left unexpressed, as in this example of Jarnail's:

17) bag in the table (JPE)

$<=$ 'put the bag on the table'> (Carroll. 1990: 1027)

or the theme may precede the (explicit) verb in the contexts discussed immediately below. If the theme has to be identified, because invisible to the performer, or one of a set, then it is simply mentioned, as in the following example of Jarnail's (even if the source relatum is mutually known, it cannot be mentioned before the theme):

18) book

$<$ the performer looks for and finds a book>

++ book in the table (JPE)

$<=$ 'put the book on the table'> (Carroll, 1990: 1027) ${ }^{27}$

${ }^{27}$ These English examples nicely show a flat surface conceptualized as a container ('in", in the absence of 'on' from Jarnail's BV). 
It is in such a context that the theme may precede the verb, as in the second mention of livre in Abdelmalek's:

19) avec un livre + livre [don] le sac (AMF)

<with a book + book 'give' (= put) the bag>

We said in Section IV.4.b above that the relatum is confined to the focus expression. This strong constraint is the consequence of the use of verbs of causative motion in this task. The 'presentational' order 'relatum-theme' (next to Chaplin (is) policeman) is confined to static locations, with the copula variant of pattern PH3 with an initial adverbial, and is rare because in the absence of a functional determiner system for most speakers of the BV word order constitutes the most functional means for distinguishing theme from relatum (Carroll, 1990; Carroll and Dietrich, 1985).

These examples show clearly how simple phrasal patterns are adapted to task and context. The constituents left implicit in example (17) can be explained by the fact that adult learners know that a 'manipulative activity scene' (Slobin, 1985) links through the notion of causative motion to a theme-relatum configuration at goal. The controller is unambiguously derivable from the context, and the specification of the spatial configuration at goal allows causative motion to be left unexpressed.

The BV thus shows regular form-function correspondences: constituent order is semantically and pragmatically constrained, is not an 'imperfect reflection* of SL or TL constraints, and is in no way random. Adult learners have communicational needs that require sequences of utterances performing a range of discourse functions, and the BV is developed, in which lexemes are combined into patterns to express a definable range of semantic and pragmatic functions. In sum, the BV is a complex of interrelations between lexical expressions, order constraints and the discourse structure of different communicative tasks.

\section{2 ... and where it fails}

The BV provides an efficient means of communication just so long as its organizing principles coalesce, where, for example, the first NP of PH1 is both controller and topic. Discourse contexts occur, however, where its constraints come into conflict: the controller may be in the focus component, or else the NP-referent in topic may not be the controller (as typically the subject of an English passive sentence). This fact has two distinct consequences: 
learners 'override' one of the constraints, or (b) they develop specific means to accommodate the 'competition' (Bates and MacWhinney, 1987).

We will illustrate the first case with reference to example (10) of Section IV. When The girl stole the bread answers the question Who stole the bread?, the focus is the person specified by the NP the girl, but this person is also the controller of the utterance. By SEM1 the NP should come first, but by PR1 it should come last. Two things are observed in such a conflict situation.

1. The competition is regularly resolved as a function of the weight of the corresponding constraint in the learner's source language. Thus, to return to example (6),

6) stealing bread girl (MPE)

discourse-pragmatic factors play an important role in constraining Punjabi word order, and the Punjabi learner Madan relaxes the semantic constraint and places the controller-thief in focus. ${ }^{28}$ Punjabi's pragmatic word order possibilities act together with its rich verbal morphology.

But, lacking any functional morphology, Italian learners of German and English rely rather on the semantic ordering constraint (for the importance of this 'cue' in comprehension studies of Italian, see e.g., Bates and MacWhinney, 1987): sacrificing the focus constraint keeps the controller in $\mathrm{NP}_{1}$ :

20) mädchen nehme brot (VIG)

<girl take bread>

'Transfer of this rather subtle type accounts for much intergroup (SL-TL pairing) variation among speakers of the BV.

2. It is communicatively important to be able to mark the focus boundary in such contexts, and this motivates some learners to develop beyond the BV. The focus marker (see note 14) is maintained by some learners in order to resolve the 'controller in focus' conflict: it functions as an embryonic cleft construction, as in this example of Ravinder's, corresponding to Madan's (6):

21) is the girl pinching the bread (RPE)

\footnotetext{
${ }^{28} \mathrm{We}$ have no explanation why he doesn't simply flip around the other argument, thus keeping the non-finite verb form in the middle. A possible explanation might be that he follows a more complicated variant of PR1. with a full ranking of focus values throughout the sentence, according to which the verb has the lowest focus value in this particular context, and the girl has the highest value.
} 
Such embryonic marking further develops in some learners towards recognizable cleft constructions. The Spanish learners in particular use, with the focus marker [se], a multifunctional particle qué, ${ }^{29}$ further analysed by the most successful learner - Gloria - into oblique que versus nominative qui:

22) [se] la dame qui a volé le pain (GFS)

<is the woman who has stolen the bread>

This example of Gloria's - an advanced learner - shows correct TL verbal morphology: she uses the passé composé. It can clearly be shown (Perdue, 1990) that in texts with an overall temporal organization morphological oppositions appear on the verb in contexts where the learner attempts to break the $\mathrm{BV}$ constraint that events be proposed and interpreted according to the principle of chronological order. Overriding this chronological constraint motivates here the development of morphology.

The second case of competition we mentioned will be illustrated by a scene from the film retelling where the protagonist in topic loses control: it could be expressed in English as 'Chaplin opens the door and gets hit over the head by a falling beam'. The problem for the learner is thus to signal both a continuity in personal reference and a discontinuity of control: it is the beam which has more 'control' over the situation than the protagonist. In English, such a constellation can be solved by 'is hit' or 'gets hit', hence some variant of the passive, a possibility not available in the BV. This is the discourse context where the first approximations to a TL oblique pronominal form are attested, in initial position of structure PH3:

23) a. [hiz] drop-on the timber (RPE)

b. [le] tombe un bois sur la tête (PSF) $<$ to him falls a beam on the head>

In both cases, the controller is placed into last position, where it belongs according to its focus status but where it violates SEM1. The first NP is marked by incipient case marking of the pronoun. Thus, these structures are a first idiosyncratic attempt to overcome the competition.

\footnotetext{
${ }^{29}$ The Spanish-speaking learners of our sample acquiring French are quick to use the formal similarity between markers of subordination in both languages, so that their learner varieties show precocious subordination with *por* and (parce) qué (Chevalier. 1986).

"'A. Giacalone Ramat points out that where TLs have a richer and more regular verb morphology than the ones of our sample - Italian and Spanish, for example - then this development is facilitated, and tends to be precocious (Giacalone Ramat. 1992).
} 
Such contexts of 'competition' provide the language acquisition researcher's contribution to question (3) of the introduction - Why are 'fully fledged' languages more complex than the BV? - as they are the seed-bed for the development of TL-specific morphosyntax. In other words, TL-specific morphosyntax allows the learner to elaborate a more cohesive organization of information in identifiable discourse contexts (Véronique, 1989; Trévise, et al., 1991; Perdue and Klein, 1992).

\section{Basic Variety and the human language capacity}

\section{A short summary}

In this section, we will put the $\mathrm{BV}$ into the somewhat broader context of how human language in general is organized. It will be helpful to start with a brief recapitulation of our findings, as presented in the preceding sections. They can be summed up in four points.

I Adult second language learners (outside the classroom) regularly develop a particular form of language, the 'BV. Some of them fossilize at this level, that is, they keep its structural properties and only enrich the lexical repertoire, whereas others complexify the variety to a greater or lesser extent.

II The lexicon of the $B V$ is essentially taken from the target language (with some borrowings from other sources). It mainly consists of (uninflected and often phonologically distorted) open-class items; closed-class items appear but are rare. Formation of new words is limited to noun-noun compounds.

III Structurally, the $B V$ is characterized by a small set of organizational principles. It is the interaction of these principles which determines, for example, the concrete form of utterances or the way in which time and space are encoded. These principles seem to be the same for all learners, irrespective of source and target language. What varies to some extent is their interaction, and in particular which constraints are abandoned in contexts where they come into conflict.

IV Strikingly absent from the BV are (a) free or bound morphemes with purely grammatical function and (b) complex hierarchical structures, in particular subordination.

Before turning to the question as to what these empirical findings may tell us about the human language capacity, some caveats are in order. First, there are some exceptions. We do not think that this is a particular problem. We are talking here about learners who 
acquire and use their language for social survival, and if they can't make themselves understood with what the BV provides them, a word or even a construction from their mother tongue - or even a third language - might easily slip in. In any event, these exceptions are rare. Second, there are some aspects of the BV which have not been investigated so far. The most important of these concern scope phenomena. Among the few closed-class items of the BV, we normally find some element to express negation, some quantifiers and some focus particles (such as also, only and their equivalents). Preliminary studies (Giacomi et al., 1994; Dimroth and Klein, 1995) indicate that they tend to precede the part of the utterance over which they have scope. But these are very first observations, and the problem awaits further investigation.

\section{Basic Variety, theory of grammar and second language acquisition}

Is the BV a 'real language', or is it just a more or less rudimentary protoform? Stated in this way, the question is hardly answerable, because the notion of 'real language' is anything but clearly defined. The BV is a highly efficient system of communication, and in this sense it is surely a real language; at the same time, it lacks some of the structural characteristics which we typically find in fully fledged languages. Are these characteristics constitutive of the language capacity which is specific to our species, or are they rather a sort of stunted growth of this capacity? Such a question only makes sense with respect to a particular theory of human language. The best known of these theories is Generative Grammar, as developed by Noam Chomsky and others since the early 1950s. In what follows, we shall discuss this question with respect to this theory. This is not easily done because, while the basic tenets of Generative Grammar have remained the same over the years, its concrete form has undergone many substantial changes. We shall base our discussion on its most recent version, as outlined in Chomsky (1995: Chapter 4). It will turn out that our findings about the BV and the key ideas of the 'Minimalist Program' are not only compatible but also naturally lead to a very simple theory of second language acquisition - or, more precisely, of the grammatical side of second language acquisition.

Many assumptions of the 'Minimalist Program' are very much in flux, but for present purposes it will suffice to consider some of its key ideas, no matter which concrete form these will eventually take. As in all variants of Generative Grammar, the human language faculty is seen to consist of a number of different components. 
among which 'I-language' plays a central role. ${ }^{31}$ Any I-language is an instantiation of Universal Grammar (UG), a particular way in which UG stabilizes after having been exposed to linguistic input from the social environment of a learner. An I-language allows its speaker to construct an infinite set of formal objects - linguistic expressions - whose structural properties can be described on various linguistic levels. Minimally, these are Phonetic Form (PF) and Logical Form (LF) and, in contrast to earlier versions of Generative Grammar, it is assumed that there are no more than these two levels. Thus, a full structural description is a pair $(\pi, \lambda)$, where $\pi$ is a PF representation, and $\lambda$ is a LF representation, respectively. Each level functions as an interface to other components of the human language faculty: $n$ is somehow interpreted by the articulatory-perceptual system, $\lambda$ is interpreted by the conceptual-intentional system, and a fundamental requirement for $\pi$ and $\lambda$ to be legitimate objects is that they must be 'interpretable' by the respective system. ${ }^{32}$

An I-language consists of a lexicon and a computational system. An element of the lexicon (lexical entry) is a complex set of features. Usually, three types of features are distinguished semantical, phonological, 'formal' (such as the categorial feature 'is a noun', or the case feature 'accusative', etc.). A lexical entry need not necessarily have all three types of features; it can be phonologically empty, or void of semantical content. It is also common to distinguish between 'substantive' categories, such as nouns, verbs, adjectives, and 'nonsubstantive' or functional categories, such as T(ense), D(eterminer), Agr(eement). The computational system selects entries from the lexicon and constructs more complex units from them ('phrases, sentences') by successive application of some operations. These are more or less

\footnotetext{
${ }^{31}$ I-language is reminiscent of "internal, individual, intensional' language, in contrast to 'Elanguage' (see Chomsky, 1986). Within the generative school, it is quite common to speak of 'language' in the sense of I-language. This is somewhat unfortunate, since the term 'language' is most often used in a much broader sense. Since this has led to endless misunderstandings and fruitless discussion, we shall strictly speak of 'I-language'. It should be clear that Ilanguage is but one of the many components of what constitutes the individual's linguistic knowledge in general (and which the learner has to know at the end of the acquisitional process).

${ }^{32}$ It should be stressed that notions such as 'grammatical' or 'well formed' play no role in this approach, quite in contrast to much of the work in SLA inspired by Generative Grammar; see. for example. Flynn (1987) or White (1989). This may well be a misunderstanding of what Generative Grammar is about; in this theory, it does not matter whether a particular structure is "grammatical' or not according to some informants but whether it can be interpreted by the relevant components of the human language faculty, cf. Chomsky (1995: 213): "The concepts "well-formed" or "grammatical" remain without characterization or known empirical justification; they played virtually no role in early work on Generative Grammar except in informal exposition, or since.'
} 
standard assumptions of all explicit linguistic theories, from Aristotle to Hjelmslev and to Montague: basically, it says that Ilanguage is an algebra. What is particular about the Minimalist Program is the radical reduction of the computational component. It is assumed that it contains only two very simple operations, MERGE and MOVE F, where F stands for 'feature'. Essentially, MERGE has taken the place of the 'phrase structure component' or of 'X-bar theory' in earlier versions of Generative Grammar, whereas MOVE $\mathrm{F}$ has taken the place of the 'transformational component' or of 'move alpha' (as constrained by principles such as 'Subjacency', etc.). We informally sketch these two operations. MERGE takes two elements (elementary elements or else the result of an earlier application of MERGE), forms a new element and labels it as being of the same category as one of its constituents (the 'head', the other being its 'complement'). MERGE says nothing about the relative order of its constituents. Thus, there is no X-bar structure, let alone a phrase structure in the traditional sense of the word (although conventional 'trees' and labels such as VP or N' continue to be used for informal presentation). MERGE is the same for all I-languages.

In a 'perfect' I-language, MERGE should suffice to generate all legitimate linguistic expressions. But for some reason - a point to which we shall return at the end of this section - elements of such an expression are often not in the position in which they are interpreted: they are 'displaced'. MOVE F is a radically simplified way to describe the 'displacement possibilities' of I-language. What is moved is not a full expression, say a maximal projection in the sense of X-bar theory, but a feature $\mathrm{F}$ (from the set of 'formal' features), and it is left to special (largely phonological) conditions whether other features of the element which contains $F$ are 'carried along'. The basic mechanism which drives MOVE F is 'feature checking'. Formal features of a lexical entry - such as 'accusative', 'plural', 'past tense' - can be 'weak' or 'strong'. Typically, though not necessarily, this distinction corresponds to the richness of morphology; in Latin, for example, 'accusative' is strong, whereas it is weak in English or in Chinese. Movement is driven by the necessary match between a (strong) feature in a functional category, say $\operatorname{Agr}($ eement), and a corresponding form, for example an inflected verb; the latter, or actually the relevant feature of the latter, has to be moved into a 'checking position' and, when checked appropriately, the resulting structure is passed on to LF. The details of this mechanism need not concern us here. What matters is the general idea that there is a strong interrelation between (rich) morphology and movement. MOVE $F$ is 'parameterized'. 
depending on which features are strong in a particular I-language. After this very brief sketch, let us now return to the BV and its status. Is it an I-language? Clearly, it has a lexicon, and the entries of this lexicon are complexes of semantic, phonological and formal features; it is not clear, though, whether the BV also has purely functional categories, a point to which we shall return. Consider first the 'computational component'. We have described the organization of the BV in terms of three constraints - phrasal, semantic, pragmatic. Ignoring the latter two for the moment, it is clear that the phrasal constraints from Section IV.2 above can easily described by MERGE (if we assume that NP is simply a convenient label for the simple or compound structures discussed in Section IV.2 above). There is apparently no counterpart to the other operation MOVE F. This seems to leave us with two clear discrepancies: (a) no functional categories and (b) no MOVE F. There is, thirdly, no morphology, at least at the surface, but this is also basically true for I-languages such as Chinese.

It is easy to see that these three facts are somehow interrelated. Let us now examine this connection, starting with the possible lack of functional categories. ${ }^{33}$ There is not full agreement on what the functional categories of I-language are; Chomsky (1995) discusses $\mathrm{T}$ (ense), D(eterminer), $\mathrm{C}$ (omplement), $\mathrm{Agr}($ eement), and it is shown that the latter is not necessary; other proposals include, for example, ASP(ect) and NEG(ation). Functional categories can, but need not, have phonological features; it is a standard assumption, for example, that in English, $\mathrm{C}$ is overtly present in subordinate clauses (for example that) but not in main clauses. Therefore, it is not easy to decide which functional categories, if any, are present in the BV; we must look for other non-phonological cues, for example the reflex of semantic or formal features typically associated with functional categories. D, for example, is semantically related to different types of referentiality, which are found and to some extent marked in the BV (see Section IV.2 above). Thus, it is

\footnotetext{
"This is a problem that has recently begun to exercise SLA researchers working in the generative tradition, who formulate it in the following terms: 'are functional categories available in the adult learner's "initial state"?' Schwarz and Sprouse (1996: 65) answer in the affirmative: the learner has available 'all the properties of the L1 computational system', and they appeal to the "knowledge/performance distinction in explaining that 'early Interlanguage utterances are often fragmentary, as well as deviant in inflectional morphology (from the perspective of the TL).' Vainikka and Young-Scholten (1996, which sums up previous work) suggest on the other hand that all that is available to the adult beginner is knowledge of lexical categories and their linear order (VP): functional projections have to be reacquired. This hypothesis would explain the absence from early learner varieties of: 'verb raising, auxiliaries and modals, an agreement paradigm, complementizers, WHmovement' (1996: 16) As we will show below, the Minimalist Program allows for a much simpler and more natural explanation of these facts.
} 
plausible that $\mathrm{D}$ is there, although its marking is optional. The case is less clear for T: as was said in Section IV.3, the BV has no inflectional marking of past, present or future. But under other theories of what 'tense' is (see. for example, Klein, 1995), there may be good reasons to assume that $\mathrm{T}$ is also present in the $\mathrm{BV}$. The functional category ASP is usually related to 'lexical aspect', i.e., the distinction between telic and atelic, resultative and non-resultative, etc. (rather than to perfective and imperfective), and aspect in this sense plays an eminent role in the BV (see SEM2 in Section IV.2 and the discussion related to this constraint); hence, ASP seems to be there. By contrast, there is no obvious reflex of $\mathrm{C}$; but again, whether it is really there or not depends on which features one assumes to be constitutive of $\mathrm{C}$.

Summing up this brief discussion, the evidence for functional categories in the Basic Varieties is quite mixed: there is evidence for semantic features of the sort typically linked to functional categories, there is no evidence for phonological features (with the possible exception of D), and there is no clear evidence for 'formal features' and their various structural consequences. Thus, the picture is quite inconsistent. But there is a natural way to account for precisely this picture: feature strength. Remember that formal features necessitate MOVE F only if the relevant feature is strong. Feature strength is parametrized: in a 'normal' I-language, some features are strong, others are weak, with the relevant structural consequences for MOVE $\mathrm{F}$. The $\mathrm{BV}$ is a radical case of parametrization:

24) In the BV, all features are weak.

This naturally accounts for all of the structural particularities of the $\mathrm{BV}$ : no inflectional morphology, no complex structures which would require some kind of movement. The BV is not only an I-language. it is a 'perfect' I-language in the sense of Chomsky (1995:9,317-18). But of course it does not exploit what is possible in an I-language. and what is normally used in I-languages. To this end, the learner has to 'strengthen' some of the features. Thus, second I-language acquisition beyond the BV is esssentially a process of selecting the appropriate features to be made strong - those which happen to be strong in the target language.

What allows the learner to make this choice? A strong feature can be identified in two ways: (a) by its structural consequences, as brought about by MOVE F and (b) by the 'rich' morphology which is typically linked to it. The first kind of evidence is clear in principle 
but often difficult to detect (it is surely not easy for a learner to unveil the structure of Who did John claim to have been told to be the friend of in the input). The second kind of evidence is much more obvious: everybody can see, or rather hear, that French varies its verbs more than English. But there are two problems. First, it is not unambiguous - rich morphology typically goes with strong features, but this is not necessarily the case; second, while it is easy to note that French has a rich verb morphology, it may be anything but easy to sort it out; in fact, the richer it is, the more difficult it may be to learn (see the discussion of the acquisition of French in Dietrich et al., 1995). Therefore, many learners, at least adult learners, may be unwilling or unable to attack this task. Children do, they have to, if they want to become a member of their social environment. ${ }^{34}$

Note that we are talking here about the acquisition of I-language, not of language at large'; that is, about all of the other components which belong to the capacity to understand and make oneself understood in English, German or whatever language. Among the organizing principles of the BV, we also noted 'semantic' constraints such as 'Controller first' and 'pragmatic' constraints, such as 'Focus last' (cf. SEM1 and PR1 from Section IV.2 above). These have no place in I-language, as it is defined in the Minimalist Program and in Generative Grammar in general. But this does not mean that they do not exist or are irrelevant. Within the Minimalist Program, they would have to find their place in other components of the language faculty, for example in the pragmatic system or in the conceptual-intensional system which interprets the interface level $X$. Not very much is said about these systems in the Minimalist Program, nor in other older versions of Generative Grammar. But, it would appear natural to restate them in terms of 'principles of interpretation', for example:

25) The referent of first noun phrase is interpreted to have the highest degree of control over the entire situation ( = SEM1)

26) The last constituent has the highest focus value ( = PR1)

Thus, constraints as 'Controller first' or 'Focus last' - whatever their

\footnotetext{
${ }^{34}$ Incidentally, it may well be that the apparent ease with which children master rich morphology and relatively complex structures at a relatively early age is quite fallacious. The mere fact that they produce complex sentences with perfect morphology does not prove at all that they have the appropriate parametrized association between feature strength and its various structural consequences; it could well be that they are just better in imitating structures, without a real understanding of the underlying principles. This could be only decided by systematic tests, but such tests have hardly ever been done.
} 
precise form might be - are not at variance with the general idea of Generative Grammar or the Minimalist Program in particular; but they have a different locus within the various knowledge components which in their entirety constitute the human language faculty. However, the syntax-semantics-pragmatics correspondences of the $\mathrm{BV}$ are so tight that these constraints appear to be central to its functioning. This brings us to the next question: Are semantic and pragmatic constraints of this type a part of 'Universal Grammar'?

There is no reason why these constraints, whatever their precise form may be, cannot belong to the genetic endowment of our species. Otherwise, we would be forced to assume that they are inductively learnt from the input, and although this is not logically excluded it is hard to imagine how it should be possible. If this is correct, however, then the innate, universal component of our language faculty goes substantially beyond I-language. Consequently, 'Universal Grammar' is much more than the initial state of I-language. This possibility is not necessarily at variance with the general idea of Generative Grammar (see, for example, Bierwisch, 1992, for such a wider perspective), but it goes far beyond what is commonly assumed to belong to UG.

This leaves us with a final question: If the BV is a 'real language', why do most (though not all) learners go beyond it? The first answer is obvious: in principle, they want to adapt to the language of their social environment, and therefore they have to find out what its strong features are. But this answer immediately leads to a more general question: Why do 'normal' I-languages go beyond such a simple parametrization? Couldn't they be much simpler in this regard? Chomsky (1995) devotes a short section (4.7.1) to the question 'Why move?', and he says:

[This] question - why do natural languages have such devices? - arose in the early days of Generative Grammar. Speculations about it invoked considerations about language use: facilitation of parsing on certain assumptions, the separation of theme-rheme structures from base-determined semantic (theta) relations, and so on. [Footnote with references omitted] Such speculations involve [...] conditions imposed on $\mathrm{C}_{\mathrm{HI}}$ [the computational system] by the way it interacts with external systems. That is where we would hope the source of 'imperfections' would lie. on minimalist assumptions (317).

We have nothing to say here about facilitation of parsing, except that the complex structures produced by MOVE F do not always seem particularly easy to parse. But what we have found in our investigation of the BV (cf. Section V.2 above) exactly confirms the second 'speculation' - an I-language fails when 'case role 
constraints' and 'focus constraints' - thus constraints which belong to 'external systems' - lead to conflicts which cannot be overcome by the structural means of a 'perfect' I-language.

\section{Language before language}

If all of this is correct, then there is no need to stipulate two essentially distinct modes of language, both provided for by the human language capacity. Such claims have been made by various authors, in particular by Givón (1979) and by Bickerton (1981; 1984; 1990). Before turning to these, we will briefly address another question which naturally rises in this context: How is the BV related to 'pidgins'?

Pidgins are normally seen as the product of some rudimentary SLA process; therefore, they should bear some similarity to the BV. In fact, it is often reported that they lack inflectional morphology, tend to an SVO word order and hardly ever have complex constructions - properties which we also find in the BV. A precise comparison, however, is quite problematic, for at least three reasons. First, there is anything but agreement on what should count as a pidgin. Hancock, for example, gives very different lists in (1971) and (1977). Second, there is apparently considerable variation between pidgins based on the same language, say English, hence no uniform structure but at best similarities (for a discussion of this and the previous problem, see Romaine, 1988: Chapter 2). Third, pidgins have hardly ever been systematically investigated with respect to organizing principles of the type discussed in Sections IV.2 to IV.4 above. Therefore, all we can say at this point is that there are certainly similarities, but it is quite unclear how farreaching these are.

Let us now come back to our earlier question. Givón (1979) postulates two extreme modes of communication: the 'pragmatic mode' and the 'syntactic mode', with the former characterizing early child language, second language and, indeed, pidgins. A speaker gradually acquires the syntactic mode, while retaining the capacity of the other mode: 'The type of communication used by adults acquiring a second language is essentially the pragmatic mode' (1979: 102). Givón suggests extralinguistic pressures from the communicative situation, and psycholinguistic pressures of efficient, automated language processing, to explain grammaticalization processes leading from the pragmatic to the syntactic mode. He sees the pragmatic mode as being poorly structured: there is no stable syntax, the one clear principle governing word order, for example, is 'go from given to new'. If this is correct, then the 'pragmatic 
mode' is something quite different from the BV. As was shown above, the BV is very highly structured. There is a very tight interplay of constraints of different types, and an appeal to just one type - Givón's pragmatic organization - does not suffice. This does not preclude, however, that the 'pragmatic mode' characterizes some form of communication which, in second language acquisition, precedes the BV, and which is also found in some forms of language called 'pidgin'.

Similar considerations apply to Bickerton's notion of a protolanguage. He writes (1990: 122): 'The evidence just surveyed gives grounds for supposing that there is a mode of linguistic expression that is quite separate from normal human language and is shared by four classes of speakers: trained apes, children under two, adults who have been deprived of language in early years, and speakers of pidgin.' If there is such a protolanguage, it is not surprising, therefore, that its functional and structural characterizations are quite different from what we found for the $\mathrm{BV}^{35}$

The 'pragmatic mode' as well as the 'protolanguage' are manifestations of some innate 'language capacity', but they are characteristically distinct from human languages. Givón's two modes, despite the processes linking them, have different structural properties and function differently. Bickerton explicitly postulates a discontinuity between 'protolanguage' and 'language': 'There is evidence, from at least two areas, that protolanguage can change into language without any intervening stage, as well as evidence ... that there can be no plausible intermediate stage between the two.' (1990: 165). In considering the BV from an acquisitional perspective, one cannot but notice the continuity of its organizing principles upstream and downstream. The weight of each type of principle varies over time, but not the nature of the principles interacting in successive learner varieties, of which 'fully fledged' languages are but the final, borderline case. ${ }^{36}$

\footnotetext{
${ }^{35}$ There are some doubts, incidentally, that early child language is indeed fully comparable to the other variants of one and the same "mode", be it the 'protolanguage' or Givón's 'pragmatic mode'. Adults - be it early second language speakers or speakers of pidgins use simple means to construct temporally and spatially contextualized utterances in connected discourse, with complex inter-utterance relations. Children produce utterances embedded in the here-and-now. These two cases cannot be subsumed under one single mode of communication.

${ }^{36}$ Another type of 'simple language' discussed in the literature is Slobin's 'Basic child grammar'. A comparison with the BV clearly illustrates the different preoccupations of the child and adult learner. The adult's task is first and foremost linguistic, whereas the child has also to identify and understand the notions relevant for grammatical construction. The BV is thus a linguistic object, and the crosslinguistic generalizations we have made are first and foremost linguistic. Basic child grammar on the other hand is a linguistic-conceptual object,
} 


\section{Second language acquisition and second I-language acquisition}

This article is not primarily about the study of second language acquisition, but about some findings from this field and what they might tell us about the human language faculty in general. But if these findings and what we conclude from them are basically correct, then this should also have some consequences for a theory of second language acquisition. In Section VI.2 above, it was argued that the BV can be naturally interpreted as an I-language with a particular feature parametrization; further acquisition beyond the $\mathrm{BV}$ is basically a process of 'feature strengthening': the learner has to find out by input analysis which features are strong in the target language. This leads to a very simple picture of the acquisition process, and it assigns the BV a natural locus in this process.

It should be very clear, however, that we are talking here about the acquisition of I-language. I-language is only a small fraction of the knowledge which is required to be a fluent speaker of a 'language'. Perfect replication of pronunciation, correct choice of noun declension paradigm, appropriate usage of present perfect vs simple past, correct identification of word meaning, appropriate usage of deictic terms, of discourse rules, of specific ways of focus marking and so on - in short, almost everything someone has to learn, when he or she wants to become a speaker of the target language, is irrelevant for this subpart of language acquisition. It is arguable, and perhaps simply a matter of personal preference, which importance one should attribute to these various components of linguistic competence. But it should be clear that there is a difference between a theory of second language acquisition and of second

and the crosslinguistic generalizations reflect this interplay - an available concept is encoded by different linguistic means (including morphology) across languages. A relevant example of this is Slobin's 'Manipulative Activity Scene", where an agent directly affects (or affects with an instrument he or she directly controls) the place or nature of an object. The child conceptualizes this scene as a Gestalt-like prototype, and seeks some salient (initially uninterpreted) linguistic means to mark the Gestalt. Slobin cites work on the acquisition of Russian (Gvozdev. 1949) and Kaluli (Schieffelin, 1985) which shows that in the first case the TL's accusative marker on objects, and in the second case the TL"s ergative marker on agents, are used early to mark the same, highly transitive (Hopper and Thompson, 1982) predicates such as 'break, hit'. The markers are used only later for less transitive predicates such as 'see. meet'. Slobin comments: 'we should expect to find particles and affixes in early child speech if they are perceptually salient and expressive of basic notions' (1985: n. 9) - basic for the child, who. in this example, is not yet using the morphology as the TL's accusative or ergative. but as a means to mark the scene. Slobin adverts to Schlesinger's (1982) process of semantic assimilation by similarity and metaphor to account for the spread of this morphology to less prototypical cases of transitivity; hence the parallel analysis of the notion which is grammaticalized in the TL. The contrast is striking with the adult speaker of the BV. who has no difficulty in assimilating prototypical and less prototypical instances of transitivity under the control constraint (SEM1), but who crosslinguistically relies on word order alone as the expressive device. 
I-language acquisition: the latter is a very small - and perhaps not particularly interesting - part of the former.

\section{Concluding remarks}

We started with the question: 'Couldn't languages be much simpler?' The answer is 'Yes, but perhaps not very much.' We have seen that adult language learners who, unlike children, do not end up by faithfully reproducing all the idiosyncrasies and oddities presented to them by their social environment, but organize their utterances and texts according to elementary principles of their innate human language capacity, regularly develop a type of language which is perfectly well structured, highly efficient - and very simple. It has definable shortcomings, though, and we assume that the attempts which the human language capacity makes to overcome these are largely responsible for all of this fabric which makes natural languages so opaque and so complex. The universal core is simple. But when it is transgressed, the complications begin.

We do not believe that our characterization of the BV, in particular the way in which the various organizational principles are stated, is the last word on this issue. Nor do we believe that there are no other sources of complexity. There might be a reason to have case morphology, but this does not justify ten different paradigms of noun inflection. We do believe, however, that the general perspective on the human language capacity and its achievements suggested here is correct.

\section{References}

Bates, E. and MacWhinney, B. 1987: Competition, variation and language learning. In MacWhinney, B., editor, Mechanisms of language learning, Hillsdale, NJ: Lawrence Erlbaum, 157-94.

Becker, A. and Carroll, M. 1997: The expression of spatial relations in a second language. Amsterdam: John Benjamins.

Bickerton, D. 1981: The roots of language. Ann Arbor: Karoma. 1984: The language bioprogram hypothesis. Behavioral and Brain Sciences 7, 173-221. 1990: Language and species. Chicago: University of Chicago Press.

Bierwisch, M. 1992: Probleme der biologischen Erklärung natürlicher Sprache. In Suchsland, P., editor. Biologische und soziale Grundlagen der Sprache, Tübingen: Niemeyer, 7-45.

Bouton, C. 1969: Les méchanismes d'acquisition du français langue étrangère chez l'adulte. Paris: Klincksieck.

Broeder, P. 1991: Talking about people: a multiple case study on adult language acquisition. Amsterdam: Swets en Zeitlinger. 
Broeder, P., Extra, G. and van Hout, R. 1993: Richness and variety in the developing lexicon. In Perdue, C, editor, Adult language acquisition: cross-linguistic perspectives. Volume 1, Field methods, Cambridge: Cambridge University Press, 145-63.

Broeder, P., Extra, G., van Hout, R. and Voionmaa, K. 1993: Word formation processes in talking about entities. In Perdue, C, editor, Adult language acquisition: cross-linguistic perspectives. Volume 2, The results, Cambridge: Cambridge University Press, 41-72.

Carroll, M. 1990: Word order in instructions in learner languages of English and German. Linguistics 28, 1011-37.

Carroll, M. and Becker, A. 1993: Reference to space in learner varieties. In Perdue, C, editor, Adult language acquisition: cross-linguistic perspectives. Volume 2, The results. Cambridge: Cambridge University Press, 119-49.

Carroll, M. and Dietrich, R. 1985: Observations on object reference in learner languages. Linguistische Berichte 98, 310-37.

Chevalier, J.-CI. 1986: Structuration d'un discours français par un migrant, apprenant en milieu naturel. Langue Française 71, 17-31.

Chomsky, N. 1986: Knowledge of language: its nature, origin and use. New York: Praeger.

1995: The Minimalist Program. Cambridge, MA: MIT Press.

Clark, E. 1971: On the acquisition of the meaning of 'before' and 'after'. Journal of Verbal Learning and Verbal Behaviour 10, 266-75.

Clyne, M. 1968: Zum Pidgin-Deutsch der Gastarbeiter. Zeitschrift für Mundartforschung 35, 130-39.

Comrie, B. 1981: Language universals and linguistic typology. Chicago: University of Chicago Press.

Corder, S.P. 1967: The significance of learners' errors. International Review of Applied Linguistics 5, 161-70.

Dietrich, R. 1989a: Communicating with few words. An empirical account of the second language speaker's lexicon. In Dietrich, R. and Graumann, G, editors, Language processing in social context. Amsterdam: North Holland, 233-76.

1989b: Nouns and verbs in the learner's lexicon. In Dechert, H., editor. Current trends in European second language acquisition research. Clevedon: Multilingual Matters, 13-23.

Dietrich, R., Klein, W. and Noyau, C, editors, 1995: The acquisition of temporality in second language acquisition. Amsterdam: John Benjamins.

Dimroth, C. and Klein, W. 1995: Fokuspartikeln in Lernervarietäten. Zeitschrift für Literaturwissenschaft und Linguistik 104, 73-114.

Dorriots, B. 1986: How to succeed with only fifty words - analysis of a role play in the frame of adult language acquisition. Göteborg Papers in Theoretical Linguistics 52-80.

Ellis, R. 1994: The study of second language acquisition. Oxford: Oxford University Press.

Feldweg, H. 1993: Transcription, storage and retrieval of data. In Perdue, $\mathrm{G}$, editor. Adult language acquisition: cross-linguistic perspectives. 
Volume1, Field methods. Cambridge: Cambridge University Press, $108-30$.

Flynn, S. 1987: A parameter setting model of L2 acquisition. Dordrecht: Reidel.

Giacalone Ramat, A. 1992: The grammaticalization of temporal and modal relations. Studies in Second Language Acquisition 14, 297-322.

Giacobbe, J. 1993: Acquisition d'une langue étrangère: cognition et interaction. Paris: CNRS Editions.

Giacomi, A., Stoffel, H. and Véronique, D. 1994: Acquisition de la portée de quelques particules en français L2. 4th EUROSLA Conference. Aix-en-Provence, September.

Givön,T. 1979: From discourse to syntax: grammar as a processing strategy. In Givón, T., editor, Syntax and semantics 12: discourse and syntax. New York: Academic Press. 81-111.

Gvozdev, A.N. 1949: Formirowanie u rebenka grammaticeskogo stroja russkogo jazyka. Moskva: Izdatelsvo Akad. ped. nauk RSFSR.

Hancock, I.F. 1971: A survey of the pidgins and creoles of the world. In Hymes, D., editor, Pidginization and creolization of languages. Cambridge: Cambridge University Press, 509-25.

1977: Repertory of pidgin and creole languages. In Valdman, A.. editor, Pidgin and creole linguistics. Bloomington: Indiana University Press, 277-94.

Haviland, J. and Levinson, S., editors, 1994: Spatial conceptualization in Mayan languages. Linguistics 32. Special issue.

Hopper, P. and Thompson, S., editors, 1982: Studies in transitivity. New York: Academic Press.

Huebner, T. 1983: The acquisition of English. Ann Arbor: Karoma. 1989: Establishing point of view: the development of coding mechanisms in a second language for the expression of cognitive and perceptual organization. Linguistics 27, 111-43.

Keenan, E. 1976: Towards a universal definition of 'subject'. In $\mathrm{Li}, \mathrm{C}$, editor, Subject and topic. New York: Academic Press.

Klein, W. 1991: Raumausdrücke. Linguistische Berichte 132, 77-114. 1994: Time in language. London: Routledge and Kegan Paul.

1995: A time-relational theory of Russian aspect. Language 71. 669-94.

Klein, W. and Dittmar, N. 1979: Developing grammars. Heidelberg: Springer Verlag.

Klein, W. and Perdue, C. 1989: The learner's problem of arranging words. In MacWhinney. B. and Bates. E., editors, The cross-linguistic study of sentence processing. Cambridge: Cambridge University Press, 292-327. , editors, 1992: Utterance structure: developing grammars again. Amsterdam: John Benjamins.

Klein, W. and von Stutterheim, C. 1987: Quaestio und referentielle Bewegung in Erzählungen. Linguistische Berichte 109. 163-83.

Labov, W. 1972: Language in the inner city. Philadelphia: University of Pennsylvania Press.

Mühlhäusler, P. 1986: Pidgin and creole linguistics. Oxford: Blackwell. 
Noyau, C. 1990: Structure conceptuelle, mise en texte et acquisition d'une langue étrangère. Langages 100, 101-14.

Perdue, C. 1987: Real beginners, real questions. In Blanc, H., Le Douaron,

M. and Véronique, D., editors, S'approprier une langue étrangère, Paris: Didier-Erudition, 196-210.

1990: Complexification of the simple clause in the narrative discourse of adult language learners. Linguistics 28, 983-1009.

, editor, 1993a: Adult language acquisition: cross-linguistic perspectives. Volume 1, Field methods. Cambridge: Cambridge University Press.

, editor, 1993b: Adult language acquisition: cross-linguistic perspectives. Volume 2. The results. Cambridge: Cambridge University Press. 1995: L'acquisition du français et de l'anglais par des adultes: former des énoncés. Paris: CNRS Editions.

1996: Pre-basic varieties: the first stages of second language acquisition. Toegepaste Taalwetenschap in Artikelen 55, 135-50.

Perdue, C. and Klein, W. 1992: Why does the production of some learners not grammaticalize? Studies in Second Language Acquisition 14, 259-72.

Reis, M. 1982: Zum Subjektbegriff im Deutschen. In Abraham, W., editor, Satzglieder im Deutschen, Tübingen: Gunter Narr, 171-211.

Romaine, S. 1988: Pidgin and creole languages. London: Longman.

Rooth, M. 1992: A theory of Focus interpretation. Natural Language Semantics 1, 75-116.

Schenning, S. and van Hout, R. 1994: Dimensional spatial relations in adult language acquisition. In Bok-Bennema, R. and Cremers, C, editors, Linguistics in the Netherlands, Amsterdam: John Benjamins, 235-46.

Schieffelin, B. 1985: The acquisition of Kaluli. In Slobin, D., editor, The cross-linguistic study of language acquisition. Volume 1. Hillsdale, NJ: Lawrence Erlbaum, 525-93.

Schlesinger, I. 1982: Steps to language: toward a theory of native language acquisition. Hillsdale, NJ: Lawrence Erlbaum.

Schumann, J. 1978: The pidginization process: a model for second language acquisition. Rowley: Newbury House.

Schwartz, B. and Sprouse, P. 1996: L2 cognitive states and Full Transfer/Full Access model. Second Language Research 12(1), 40-72.

Selinker, L. 1972: Interlanguage. International Review of Applied Linguistics 10,209-31.

Silverstein, M. 1976: Hierarchy of features and ergativity. In Dixon, R., editor. Grammatical categories in Australian languages. New Jersey: Humanities Press.

Slobin, D.I. 1985: Cross-linguistic evidence for the language-making capacity. In Slobin, D., editor, The cross-linguistic study of language acquisition. Volume 2. Hillsdale, NJ: Lawrence Erlbaum, 1157-256.

Starren, M. 1996: Temporal adverbials in adult second language acquisition. Ms., MPI für Pycholinguistik, Nijmegen.

Stechow, A. von 1991: Current issues in the theory of focus. In Stechow, 
A. von and Wunderlich, D., Semantics: an international handbook of current research, Berlin: De Gruyter, 804-25.

Stutterheim, C. von 1986: Temporalität in der Zweitsprache: eine Untersuchung zum Erwerb des Deutschen durch türkische Gastarbeiter. Berlin: De Gruyter.

Trévise, A. and Porquier, R. 1986: Second language acquisition by adult immigrants: exemplified methodology. Studies in Second Language Acquisition 8, 265-75.

Trévise, A., Perdue, C. and Deulofeu, J. 1991: Word order and discursive coherence in L2. In Appel, G. and Dechert, H., editors, A case for psycholinguistic cases, Amsterdam: John Benjamins, 163-76.

Vainikka, A., and Young-Scholten, M. 1996: Gradual development of L2 phrase structure. Second Language Research 12(1), 7-39.

Véronique, D. 1983: Observations préliminaires sur 'li'. In Véronique, D., editor, Acquisition du français par des travailleurs marocains, Aix: Presses de l'Université de Provence, 155-80.

1989: Reference and discourse structure in the learning of French by adult Moroccans. In Dechert, H., editor, Current trends in European second language acquisition research, Clevedon: Multilingual Matters, 171-201.

White, L. 1989: Universal Grammar and second language acquisition. Amsterdam: John Benjamins. 